\title{
Risk AND FATE of RESidual InTERATRial SHUnting AFTER Transcatheter Closure of Patent Foramen Ovale: A LONG TERM Follow Up STUdy
}

\author{
C. Hammerstingl ${ }^{1}$, G. Bauriedel ${ }^{2}$, C. Stüsser ${ }^{1}$, D. Momcilovic ${ }^{1}$, I. Tuleta ${ }^{1}$, G. Nickenig ${ }^{1}$, D. Skowasch ${ }^{1}$ \\ ${ }^{1}$ Medizinische Klinik und Poliklinik II, Department of Cardiology, Angiology and Pneumology, University of Bonn, Bonn, Germany, \\ ${ }^{2}$ Klinik für Innere Medizin III, Kreiskrankenhaus Schmalkalden, Schmalkalden, Germany
}

\begin{abstract}
Background: Percutaneous transcatheter closure of patent foramen ovale (PFO) in cryptogenic stroke is an alternative to medical therapy. There is still debate on different outcome for each currently available device. The impact of residual shunting after PFO-closure on recurrent arterial embolism is unknown.

Aims: (i) To evaluate the prevalence of residual interatrial shunting after device- closure of PFO, (ii) to identify risk factors predicting residual interatrial shunting after device implantation, and (iii) to investigate the outcome of patients after PFO-closure during longterm follow- up (FU).

Methods and results: Between 2000- 2005 PFO-closure was performed in 124 patients using four different devices: Amplatzer PFO- $(\mathrm{n}=52)$, CardioSeal ( $\mathrm{n}=33$ ), Helex $(n=23)$ and Premere $(n=16)$ occluder. All patients underwent serial contrast-enhanced transesophageal echocardiography (TEE) for 24 months after PFO- closure; clinical FU was at minimum 5 years up to 9.75 years (mean $6.67 \pm 1.31$ years). Overall-closure rate was $87 \%$ at 2 years, device-specific closure time curves differed significantly ( $\mathrm{p}$-logrank $=0.003)$. Independent risk factors for residual-shunting were implantation of a Helex occluder (hazard ratio [HR] 12.6, 95\% confidence interval $[\mathrm{CI}] 2.6-57.4, \mathrm{p}=$ 0.002), PFO- canal- lengths (HR 1.2, 95\% CI 1.1- 1.3, $\mathrm{p}=0.004)$ and extend of atrial-septal-aneurysm (HR $1.1,95 \%$ CI $0.9-1.3$; $p=0.05) .4(3.2 \%)$ arterial embolic events occurred during a FU-period of 817.2 patient-years, actuarial annual thromboembolic-risk was $0.49 \%$. All ischemic events were not related to residual PFO-shunting or device-related thrombus- formation. Conclusion: Success rates of PFO- closure are mainly dependent on occluder-type, extend of concomitant atrial-septum-aneurysm and PFO-canal- length. Importantly, residual shunting after PFO-closure was not associated with recurrence of arterial embolism during long-term follow-up.
\end{abstract}

\section{OBjective}

Patent foramen ovale (PFO) is an important cause of paradoxical embolism. PFO presence alone increases the risk of recurrent events 5-fold, with an even higher risk in case of concomitant atrial septal aneurysm [1-3]. Transcatheter PFO closure to prevent recurrent events bears a low risk and is technically feasible with high success rates [2, 4-11]. Anzola et al. showed that there are $9 \%$ of patients left with residual shunt at 1 year post interventional PFO closure [12]. However, there is still the question of clinical outcome for different catheter devices and the relevance of residual shunting on the recurrence of ischemic events during long term follow-up (FU) [13].

The aims of this prospective cohort study were (i) to evaluate the incidence of residual interatrial shunting after interventional PFO- closure, (ii) to identify risk factors predicting residual interatrial shunting after successful device implantation and (iii) to investigate the outcome of patients after PFO- closure during a long- term FU period of at minimum 5 years, focused on the recurrence of arterial embolism after device implantation.

\section{Methods And Material}

In a prospective observational monocenter cohortstudy, symptomatic patients with documented PFO undergoing interventional PFO-closure were enrolled between May 2000 and April 2005 at the Department of Cardiology, University of Bonn, Germany. Patients with other identified causes for systemic embolism were excluded from the study. PFO closure was performed using four different devices according to device and size availability:

1. Amplatzer PFO Occluder (AGA Medical, Minneapolis, Minn., US; Diameter 25 and $35 \mathrm{~mm}$ ); 2. CardioSeal Occluder (NMT Medical, Boston, Mass., US; Diameter 23, 28 and $33 \mathrm{~mm}$ ); 3. Helex Occluder (GOREMedical Flagstaff, Ariz., US; Diameter: 15, 20, 25, 30 and $35 \mathrm{~mm}$ ); 4. and Premere Occluder (St. Jude Medical, St. Paul, Minn. US; Diameter: 20 and $25 \mathrm{~mm})$.

The study was approved by the local ethics committee, and all patients were asked to give their informed consent. 


\section{FOLLOW UP PROCEDURE}

Follow-up contrast enhanced transesophageal echocardiography (TEE) after Valsalva manoeuver were performed in all patients on days 1, 7 and 28 , and on months 3, 6, 12 and 24. At time of TEE, the patients underwent clinical FU examination for new onset of arterial embolism. After completion of echocardiographic FU-procedures, all patients were contacted 6 monthly by telephone call for the occurrence of clinical endpoints, minimum FU period was 5 years.

\section{ECHOCARDIOGRAPHY}

Two-dimensional contrast enhanced echocardiography was performed with commercially available ultrasound scanner (Vivid 7, GE Medical Systems, Wankesha, WI, and iE33, Philips, Andover, Massachusetts). A broadband transthoracic transducer and a multiplane transesophageal $5-\mathrm{MHz}$ transducer were used. For TTE and TEE a 20 gauge intravenous catheter was introduced into the right antecubital vein. As right heart contrast agent EchoVist (EchoVist ${ }^{\circledR}$, Schering, Berlin, Germany) was administered with a bolus injection of 2-5 $\mathrm{ml}$ as needed for complete opacification of the right heart chambers. The Valsalva-maneuver was conducted at each study visit and repeated until opacifation of the right atrium and interatrial septum after valsalva manoeuvre was considered of sufficient quality $[14,15]$. A PFO or residual shunt was determined on contrast appearance of micro bubbles within three cardiac cycles following opacification of the right atrium. The images were reviewed during the procedure and offline by a single experienced observer. Atrial septal aneurysm (ASA) was defined as a membrane excursion of the interatrial septum of at least $10 \mathrm{~mm}$ with a base diameter of the aneurysm of at least 15 $\mathrm{mm}$. Under TEE spontaneous or induced right-toleft-shunt was defined as grade 0 if no bubbles could be detected. Grade 1 was attributed if less than 10 bubbles were seen. Grade 2 was defined if more or equal than 10 bubbles up to a distinct contrast jet opacification was seen and grade 3 if a severe filling of more than $25 \%$ of a left heart chamber was recorded. Grade 2 and 3 were regarded as significant shunts [5, 8].

\section{DEVICE IMPLANTATION}

The PFO was crossed under fluoroscopic and TEE guidance with a 4 or $6 \mathrm{~F}$ multipurpose catheter. Depending on the occluder-type either a 9 to 12 French long sheath was placed across the atrial septum or a short 12 French sheath with an over the wire technique was used. After thoroughly flushing the loaded implantation system to prevent air embolism the device was placed under fluroscopic and TEE guidance Discharge from the hospital was on the next day after post-interventional T'TE/ TEE and 12 lead-ECG examination. After implantation of PFO-occluder all patients received dual antiplatelet therapy with clopidogrel and aspirin for 3 months, therafter aspirin was given until 12 months after the procedure. In subjects with residual interatrial shunting during TEE, an- tiplatelet-therapy with aspirin was extended until echocardiography confirmed complete PFO- closure,

\section{Clinical FOLLOW-UP}

Clinical apparent arterial embolism was defined as ischemic stroke, transient ischemic attack, myocardial infarction, or systemic embolism. All patients with recurrent arterial embolism underwent additional contrast-TEE for evaluation of the occluder system and septal anatomy. All documented arterial ischemic events during the follow- up period were considered to be PFO related unless further clinical evaluation confirmed other source of embolism.

\section{STATISTIC}

Comparison of numerical variables was performed with the Student $\mathrm{t}$ test or Wilcoxon rank sum test, depending on variable distribution. The chi-square test or Fischer's exact test was used to compare qualitative variables. Comparison between groups was analyzed with one-way analysis of variance (ANOVA) with Bonferri's post-tests. A Cox multivariate analysis including all variables with $\mathrm{p}$ value $<0.2$ in the Cox univariate analysis was used to determine the predictive factors of cumulative late mortality. Survival rates up to 5 years were presented as Kaplan-Meier curves, and the logrank test was used for comparison between groups. Differences were considered statistically significant at $\mathrm{p}$ values $<0.05$. The data were analyzed with SPSS statistical software version 17 (SPSS Inc., Chicago, IL).

\section{RESULTS}

A consecutive series of 124 patients (31-76 years) with a history of $\geq 1$ paradoxical embolism, of that 70 $(54.8 \%)$ with concomitant atrial septal aneurysm (ASA) were treated with an Amplatzer PFO Occluder, $\mathrm{n}=52$; CardioSeal Occluder, $\mathrm{n}=33$; Helex Occluder, $\mathrm{n}=23$; and Premere Occluder, $\mathrm{n}=16$.

Mean-FU-period was $6.7 \pm 1.3$ years (range 5-9.75 years), overall 827.17 patient years were reviewed for the occurrence of clinical endpoints.

\section{Procedural DETAILS}

The 4 patients groups did not differ significantly with respect to clinical variables such as age, sex and concomitant medication. In all patients, occluder devices were successfully implanted. In 1 case, an Amplatzer PFO occluder that had embolized into the pulmonary artery $24 \mathrm{~h}$ post implantation was percutaneously trapped, subsequently followed by the re-implantation of a PFO occluder with bigger diameter during the same procedure (baseline characteristics and procedural details are listed in Table 1).

\section{REsidual SHunting AFTER SUCCESSFul PFO-CLOSURE}

Closure rates increased from $65.3 \%$ immediately postprocedure up to $82.3 \%$ after 6 months, $84.7 \%$ at 12 months and $87.1 \%$ at 24 months. All patients were 
Table 1. Baseline characteristics and procedural details at time of PFO-closure.

\begin{tabular}{|c|c|c|c|c|c|c|c|c|}
\hline \multirow[b]{2}{*}{ Demographic data } & \multicolumn{2}{|l|}{$\underset{52}{\text { Amplatzer }}$} & \multicolumn{2}{|c|}{$\begin{array}{l}\text { CardioSeal } \\
33\end{array}$} & \multirow[t]{2}{*}{$\begin{array}{c}\text { Helex } \\
23\end{array}$} & \multicolumn{3}{|c|}{$\begin{array}{l}\text { PREMERE } \\
16\end{array}$} \\
\hline & & & & & & & & \\
\hline Age & 50.7 & \pm 12.9 & 47.3 & \pm 14.1 & 44.4 & \pm 11.1 & 55.6 & \pm 13.1 \\
\hline Male & 28 & $53.8 \%$ & 18 & $54.5 \%$ & 7 & $30.4 \%$ & 5 & $31.3 \%$ \\
\hline Female & 24 & $46.15 \%$ & 15 & $45.45 \%$ & 16 & $69.57 \%$ & 11 & $68.75 \%$ \\
\hline Follow-up [months] & 87.8 & \pm 19.6 & 75.0 & \pm 9.6 & 79.4 & \pm 8.4 & 54.6 & \pm 3.0 \\
\hline CAD & 13 & $25.0 \%$ & 5 & 15.2 & 3 & $13.0 \%$ & 7 & $43.8 \%$ \\
\hline Hyperlipidemia & 27 & $51.9 \%$ & 14 & $42.4 \%$ & 12 & $52.2 \%$ & 9 & $56.3 \%$ \\
\hline Hypertension & 26 & $50.0 \%$ & 10 & $30.3 \%$ & 8 & $34.8 \%$ & 6 & $37.5 \%$ \\
\hline Smoking & 15 & $28.8 \%$ & 8 & $24.2 \%$ & 2 & $8.7 \%$ & 2 & $12.5 \%$ \\
\hline Diabetes mellitus & 2 & $3.8 \%$ & 1 & $3.0 \%$ & 1 & $4.3 \%$ & 2 & $12.5 \%$ \\
\hline BMI $(\mathrm{kg} / \mathrm{m} 2)$ & 27.2 & \pm 4.6 & 25.3 & \pm 3.9 & 24.4 & \pm 4.5 & 25.9 & \pm 3.9 \\
\hline Peripheral embolism & 3 & $5.8 \%$ & 2 & $6.1 \%$ & 2 & $8.7 \%$ & 0 & $0.00 \%$ \\
\hline Central embolism & 4 & $7.7 \%$ & 3 & $9.1 \%$ & 2 & $8.7 \%$ & 1 & $6.3 \%$ \\
\hline TIA & 17 & $32.7 \%$ & 11 & $33.3 \%$ & 13 & $56.5 \%$ & 9 & $56.3 \%$ \\
\hline Stroke & 36 & $69.2 \%$ & 22 & $66.7 \%$ & 9 & $39.1 \%$ & 12 & $75.0 \%$ \\
\hline \multicolumn{9}{|l|}{ Medication } \\
\hline Aspirin & 24 & 46.2 & 14 & 42.4 & 10 & 43.5 & 11 & $68.8 \%$ \\
\hline VKA & 7 & 13.5 & 7 & 21.2 & 5 & 21.7 & 1 & $6.3 \%$ \\
\hline Clopidogrel & 1 & 1.9 & 2 & 6.1 & 1 & 4.3 & 4 & $25.0 \%$ \\
\hline ACEI & 8 & 15.4 & 5 & 15.2 & 1 & $2.0 \%$ & 2 & $12.5 \%$ \\
\hline Statins & 10 & 19.2 & 5 & 15.2 & 2 & 8.7 & 3 & $18.8 \%$ \\
\hline Diuretics & 1 & 1.9 & 0 & 0 & 0 & $0 \%$ & 1 & $6.3 \%$ \\
\hline $\mathrm{CCB}$ & 2 & 3.8 & 0 & 0 & 0 & $0 \%$ & 2 & $12.5 \%$ \\
\hline \multicolumn{9}{|l|}{ Echocardiographic data } \\
\hline Ejection fraction & 56.4 & \pm 6.8 & 57.3 & \pm 5.0 & 57.1 & \pm 4.7 & 57.2 & \pm 7.3 \\
\hline Left atrial diameter (mm) & 39.6 & \pm 3.7 & 40.0 & \pm 4.4 & 39.45 & \pm 3.4 & 40.3 & \pm 4.9 \\
\hline ASA & 27 & $51.9 \%$ & 17 & $51.2 \%$ & 10 & $43.5 \%$ & 14 & $85.7 \%$ \\
\hline Chiari network & 1 & $1.9 \%$ & 3 & $9.1 \%$ & 2 & $8.7 \%$ & 1 & $6.3 \%$ \\
\hline Eustachian valve & 14 & $26.9 \%$ & 3 & $9.1 \%$ & 3 & $13.0 \%$ & 4 & $25.0 \%$ \\
\hline \multicolumn{9}{|l|}{ Procedural data } \\
\hline Procedural success [\%] & 100 & & 100 & & 100 & & 100 & \\
\hline$>1$ placement attempt & 6 & 11.5 & 2 & $6.1 \%$ & 3 & $13.0 \%$ & 0 & $0 \%$ \\
\hline Device size $(\mathrm{mm})$ & $22-35$ & & $17-33$ & & $20-35$ & & $20-25$ & \\
\hline \multicolumn{9}{|l|}{ Procedural complications } \\
\hline Device embolization & 1 & $1.9 \%$ & 0 & $0 \%$ & 0 & $0 \%$ & 0 & $0 \%$ \\
\hline Air embolization & 0 & $0 \%$ & 1 & $3.03 \%$ & 0 & $0 \%$ & 0 & $0 \%$ \\
\hline Pericardial effusion & 1 & $1.9 \%$ & 0 & $0 \%$ & 0 & $0 \%$ & 0 & $0 \%$ \\
\hline Paroxysmal atrial fibrillation & 1 & $1.9 \%$ & 1 & $3.03 \%$ & 0 & $0 \%$ & 0 & $0 \%$ \\
\hline
\end{tabular}

$\mathrm{BMI}=$ body mass index, TIA $=$ transitory ischemic attack, $\mathrm{VKA}=$ vitamin-K-antagonist, $\mathrm{ACEI}=$ angiotensin convertin enzyme inhibitor, $\mathrm{CCB}=$ calcium canal blocker, $\mathrm{CAD}=$ coronary artery disease, $\mathrm{ASA}=$ atrial septal aneurysm.

clinically asymptomatic. Closure rates at months 3,6 , 12 , and 24 were 88.5, 88.5, 92.3, 94.2\% with the Amplatzer-device; 81.8, 84.8, 87.9, 90.9\% using the CardioSeal device; $87.5,87.5,87.5,87.5 \%$ after using the Pemere occluder and 60.9, 60.9, 62.3, 65.2\% for Helex occluders, (Figures 1 and 2).

The observed differences in time-to-closure-rates were statistically significant $(\mathrm{p}-$ logrank $=0.003$, figure 2), this difference was predominantly driven by a high rate of residual interatrial shunting after implan- tation of a Helex-device, p-values for comparison between different occluder types after 24 months are given in Table 2.

\section{RISK FACTORS FOR RESIDUAL INTERATRIAL SHUNT}

Results of univariate and multivariate analysis are given in Tables $3 \mathrm{a}$ and $3 \mathrm{~b}$. Independent predictors for residual interatrial shunt after technical successful percutaneous closure of $\mathrm{PFO}$ were implantation of a 


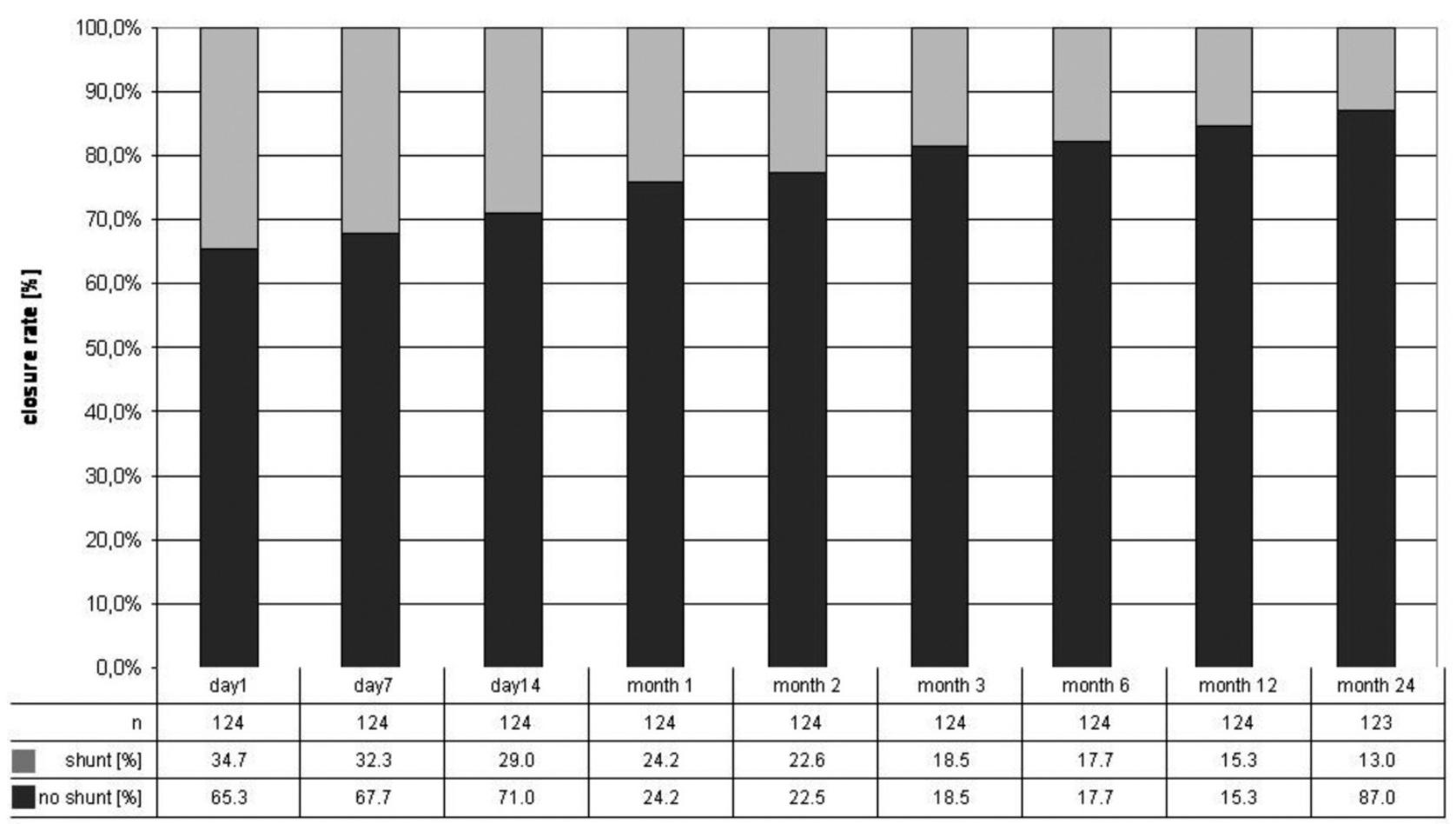

Fig. 1. TEE results indicating device related closure rates during follow up.

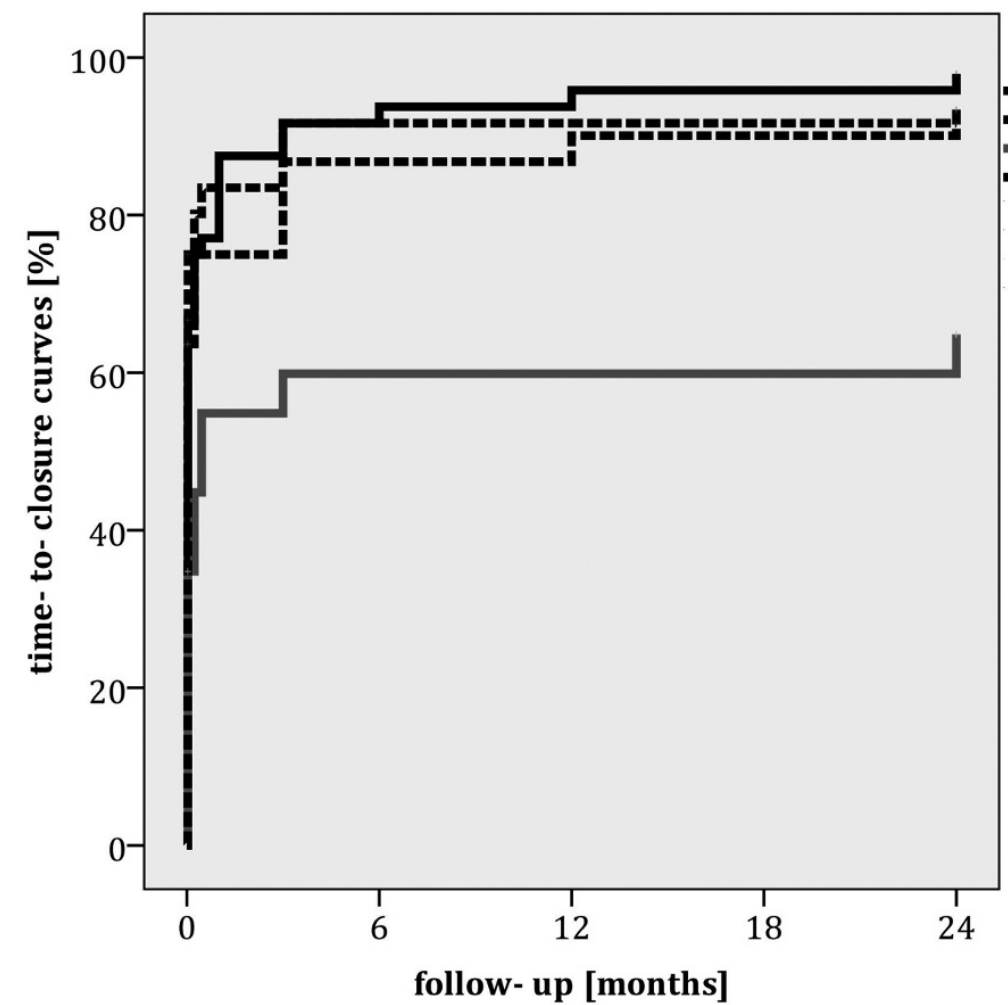

device

$\boldsymbol{I P F O - A m p l a t z e r}$ $-1=$ Cardio Seal Helex - $=$ Fremere
Helex device (hazard ratio [HR] 12.58, 95\% confidence interval [CI] 2.57-57.43, p=0.002), PFO-canallengths [per mm] (HR 1.17, 95\%CI 1.05- 1.31, p = $0.004)$ and extend of ASA [per mm] (HR 1.13, 95\% $0.95-1.29 ; \mathrm{p}=0.05)$. The width of $\mathrm{PFO}$ and pre-procedural determined severity of inter-atrial shunting were not predictive for residual shunting after 24 months.
Fig. 2. TEE results indicating device related closure rates after 24 months.

\section{Clinical outcome DATA}

During $6.67 \pm 1.31$ years 4 arterial embolic events occurred in 3 of 124 patients (2.4\%). Reviewing 817.17 patient-years, the actuarial annual thromboembolic risk was $0.49 \%$. All ischemic events occurred in patients without incidence of residual interatrial shunt during contrast enhanced TEE. One patient experi- 
Table 2. Comparison of different occluder types regarding the observed closure rates after 24 months.

\begin{tabular}{l|c|c|c|c|c|}
\hline & Amplatzer & CardioSeal & Helex & Premere & \\
\hline Amplatzer & & 1.0 & $<0.0001$ & 1.00 \\
\hline CardioSeal & & & 0.004 & 1.00 \\
\hline Helex & & & & 0.065 \\
\hline Premere & & & & \\
\hline
\end{tabular}

Table $3 a$. Univariate analysis of single variables predicting residual interatrial shunting after interventional PFO- closure.

\begin{tabular}{lrrrr}
\hline Factor & HR & & $\mathbf{9 5 \%} \mathbf{C I}$ & $\mathbf{p}$ \\
\hline Premere & 1,628 &, 052 & 51,027 &, 782 \\
Cardioseal & 3,697 &, 486 & 28,156 &, 207 \\
Helex & 19,048 & 2,409 & 150,639 &, 005 \\
PFO length [mm] & 1,162 &, 998 & 1,353 &, 054 \\
ASA[mm] & 1,130 &, 950 & 1,344 &, 169 \\
Eustachian valve & 2,508 &, 461 & 13,652 &, 287 \\
Chiari network & 3,758 &, 510 & 27,722 &, 194 \\
Severity of shunting & 1,012 &, 998 & 1,026 &, 091 \\
\hline
\end{tabular}

$\mathrm{HR}=$ hazard ratio, $\mathrm{CI}=$ confidence interval, $\mathrm{ASA}=$ atrial septum aneurysm, $\mathrm{PFO}=$ persistent foramen ovale, Eustach $=$ prevalence of Eustachien valve, Chiari $=$ prevalence of chiari-net

Table $3 \mathrm{~b}$. Multivariate-regression analysis for the most predictive factors for residual shunting after PFO-closure.

\begin{tabular}{rrrrr}
\hline Factor & HR & & $\mathbf{9 5 \%}$ CI & p \\
\hline Helex & 12.58 & 2.573 & 57.438 &, 002 \\
PFO-length & 1,173 & 1.052 & 1,307 &, 004 \\
ASA & 1,130 &, 950 & 1,29 &, 05 \\
\hline
\end{tabular}

$\mathrm{HR}=$ hazard ratio, $\mathrm{CI}=$ confidence interval, $\mathrm{PFO}=$ persistent foramen ovale, $\mathrm{ASA}=$ atrial septum anurysm.

enced two transitory ischemic attacks due to carotid plaques, another patient was hospitalized with acute peripheral leg ischemia due to embolization of an abdominal aortic plaque and one patient experienced a major-stroke after new onset of atrial-fibrillation with echocardiographic proven thrombus formation within the left atrial appendage.

Echocardiography after arterial embolism showed correct function of the occluder device. Statistical analysis failed to identify risk factors predicting recurrent embolism.

In 1 case, a PFO was closed surgically due to a minimal residual shunt, despite this patient remained asymptomatic after percutaneous PFO-closure.

\section{Discussion}

This is the first prospective study aiming to investigate the incidence, predictors and clinical impact of persistent interatrial shunting after successful interventional closure of PFO during a long term follow up period. Importantly, all patients underwent serial TEE exami- nations for 24 months after the procedure and clinical outcome data were acquired with a minimum FU period was 5 years.

The most important findings of this study are, that (i) the prevalence of residual shunting after PFO-closure is relatively high with $13 \%$ after two years, (ii) interventional success mainly depends on the choice of closure- device and, (iii) the annual risk for recurrent arterial embolism after technical successful PFO- closure is relatively low with $0.49 \%$ per patient-year, and seems independent of persistent interatrial shunting.

$$
\text { Available Data }
$$

Anzola et al. investigated 140 patients undergoing serial contrast-enhanced transcranial Doppler ofter sucesseful percutaneous PFO-closure. During Valsalva-strain a large shunt was detectable in $9 \%$ of patients after 12-months. Only 1 ischemic event occured in a patient with complete PFO closure [12]. The patients in this study did not undergo serial TEE- examinations after PFO- closure; therefore, device-related thrombi could not be excluded as well as minor- resid- 
ual shunts as potential source of embolism and clinical FU was limited to 12 moths.

More recently Von Bardeleben et al. examined 357 patients undergoing PFO closure [16], after a mean follow up period of 3.8 years the re-event rate of ischemic thromboembolism was $0.7 \%$ per patient year. No relation to residual PFO-shunting or to thrombus formation was seen, which is in concordance with our results. However, FU- period in our study population was significantly longer and we can confirm, that the event- rate remains low after more than 5 years of FU.

In contrast to our data Windecker S et al. investigated in 199480 patients after percutaneous PFO closure focussing on the long-term risk of recurrent thromboembolic events [17]. Interestingly, in this cohort study the actuarial annual risk for recurrent thromboembolic events was $3.4 \%$ and the extent of postprocedural shunt was the most important predictor for recurrent paradoxical embolism. These early data must be interpreted with caution, since occluder-devices and implantation-techniques may have improved over the following years.

\section{CLINICAL IMPACT OF RESIDUAL SHUNT AFTER TECHNICAL SUCCESSFUL PFO CLOSURE}

Closure of PFO is technical feasible with high acute success rates. The number of patients is consistently increasing despite debate is still going on if this intervention really helps to diminish recurrent ischemic events since data from prospective randomized studies are lacking [5, 18-22]. Residual interatrial shunting after PFO-closure is a frequent finding [12] and the impact on the patients' clinical outcome is unclear and not systematically investigated. In this context our data are very important, as we show, that the occurrence of arterial embolism after PFO closure is not related to residual interatrial shunt. As a consequence, routine TEE follow up after technical successful PFO-closure seems not necessary in asymptomatic individuals.

\section{LIMITATIONS}

This study is limited by the single site data collection and the non- randomized fashion. We cannot exclude decision bias from the referring physicians. In our study FU after 24 months was performed by telephone call which helped to minimize the drop- outrate. The predictable value of the identified prognostic variables must be tested prospectively before a validated risk score can be established.

\section{CONCLUSION}

Although residual shunts may be documented soon after device implantation, they consistently decrease over time and residual shunt is detectable in about $13 \%$ of patients after two years of follow up. Transient residual shunting was found more frequent with PFO closure using the Helex (in up to 30-40\%) than the Amplatzer, Premere or CardioSeal occluder. Predictors for residual shunts are PFO- anatomy and the choice of closure device. Clinically, these residual shunts were not accompanied by recurrent thromboembolic events after a long term follow up period of at minimum 5 years, and the observed embolic event rate is low.

Conflict of interest: Nothing to declare.

\section{REFERENCES}

1. Homma S, Di Tullio MR, Sacco RL, Mihalatos D, Li MG, Mohr JP. Characteristics of patent foramen ovale associated with cryptogenic stroke. A biplane transesophageal echocardiographic study. Stroke 1994; 25(3):582-586.

2. Homma S, Sacco RL. Patent foramen ovale and stroke. Circulation 2005; 112(7):1063-1072.

3. Lechat P, Mas JL, Lascault G, Loron P, Theard M, Klimczac $\mathrm{M}$ et al. Prevalence of patent foramen ovale in patients with stroke. N Engl J Med 1988; 318(18):11481152.

4. Windecker S, Meier B. Is closure recommended for patent foramen ovale and cryptogenic stroke? Patent foramen ovale and cryptogenic stroke: to close or not to close? Closure: what else! Circulation 2008; 118(19):19891998.

5. Homma S, Sacco RL, Di Tullio MR, Sciacca RR, Mohr JP. Effect of medical treatment in stroke patients with patent foramen ovale: patent foramen ovale in Cryptogenic Stroke Study. Circulation 2002; 105(22):2625-2631.

6. Bruch L, Parsi A, Grad MO, Rux S, Burmeister T, Krebs $\mathrm{H}$ et al. Transcatheter closure of interatrial communications for secondary prevention of paradoxical embolism: single-center experience. Circulation 2002; 105(24):28452848.

7. Braun MU, Fassbender D, Schoen SP, Haass M, Schraeder R, Scholtz W et al. Transcatheter closure of patent foramen ovale in patients with cerebral ischemia. J Am Coll Cardiol 2002; 39(12):2019-2025.

8. Webster MW, Chancellor AM, Smith HJ, Swift DL, Sharpe DN, Bass NM et al. Patent foramen ovale in young stroke patients. Lancet 1988; 2(8601):11-12.

9. Schwerzmann M, Windecker S, Wahl A, Mehta H, Nedeltchev K, Mattle H et al. Percutaneous closure of patent foramen ovale: impact of device design on safety and efficacy. Heart 2004; 90(2):186-190.

10. Braun M, Gliech V, Boscheri A, Schoen S, Gahn G, Reichmann $\mathrm{H}$ et al. Transcatheter closure of patent foramen ovale (PFO) in patients with paradoxical embolism. Periprocedural safety and mid-term follow-up results of three different device occluder systems. Eur Heart J 2004; 25(5):424-430.

11. Cifarelli A, Musto C, Parma A, Pandolfi C, Pucci E, Fiorilli $\mathrm{R}$ et al. Long-term outcome of transcatheter patent foramen ovale closure in patients with paradoxical embolism. Int J Cardiol 2010; 141(3):304-310.

12. Anzola GP, Morandi E, Casilli F, Onorato E. Does transcatheter closure of patent foramen ovale really "shut the door?" A prospective study with transcranial Doppler. Stroke 2004; 35(9):2140-2144.

13. Daniel WG. Transcatheter closure of patent foramen ovale. Therapeutic overkill or elegant management for selected patients at risk? Circulation 1992; 86(6):2013-2015.

14. Droste DW, Silling K, Stypmann J, Grude M, Kemeny V, Wichter $T$ et al. Contrast transcranial doppler ultrasound in the detection of right-to-left shunts : time window and threshold in microbubble numbers. Stroke 2000; 31(7): 1640-1645.

15. Schuchlenz HW, Saurer G, Weihs W. Patent foramen ovale, atrial septal aneurysm, and recurrent stroke. N Engl J Med 2002; 346(17):1331-1332. 
16. von Bardeleben RS, Richter C, Otto J, Himmrich L, Schnabel R, Kampmann C et al. Long term follow up after percutaneous closure of PFO in 357 patients with paradoxical embolism: Difference in occlusion systems and influence of atrial septum aneurysm. Int J Cardiol 2009; 134(1):33-41.

17. Windecker S, Wahl A, Chatterjee T, Garachemani A, Eberli FR, Seiler C et al. Percutaneous closure of patent foramen ovale in patients with paradoxical embolism: long-term risk of recurrent thromboembolic events. Circulation 2000; 101(8):893-898.

18. Meier B, Lock JE. Contemporary management of patent foramen ovale. Circulation 2003; 107(1):5-9.

19. Messe SR, Silverman IE, Kizer JR, Homma S, Zahn C, Gronseth $G$ et al. Practice parameter: recurrent stroke with patent foramen ovale and atrial septal aneurysm: report of the Quality Standards Subcommittee of the American Academy of Neurology. Neurology 2004; 62(7):10421050.

20. Messe SR, Kasner SE. Is closure recommended for patent foramen ovale and cryptogenic stroke? Patent foramen ovale in cryptogenic stroke: not to close. Circulation 2008; 118(19):1999-2004.

21. Mohr JP, Homma S. Patent cardiac foramen ovale: stroke risk and closure. Ann Intern Med 2003; 139(9):787-788.

22. O'Gara PT, Messe SR, Tuzcu EM, Catha G, Ring JC. Percutaneous device closure of patent foramen ovale for secondary stroke prevention: a call for completion of randomized clinical trials: a science advisory from the American Heart Association/American Stroke Association and the American College of Cardiology Foundation. Circulation 2009; $119(20): 2743-2747$.
23. Khairy P, O'Donnell CP, Landzberg MJ. Transcatheter closure versus medical therapy of patent foramen ovale and presumed paradoxical thromboemboli: a systematic review. Ann Intern Med 2003; 139(9):753-760.

24. Coats AJ. Ethical authorship and publishing. Int J Cardiol 2009; 131(2):149-150.

Received: December 10, 2010 / Accepted: December 21, 2010

Address for correspondence:

Dr. Christoph Hammerstingl

Medizinische Klinik und Poliklinik II

Universitätsklinikum Bonn

Sigmund Freud Str. 25

53105 Bonn

Germany

Tel.: $\quad+49-228-28716670$

Fax: $\quad+49-228-28714907$

E-mail: christoph.hammerstingl@ukb.uni-bonn.de 